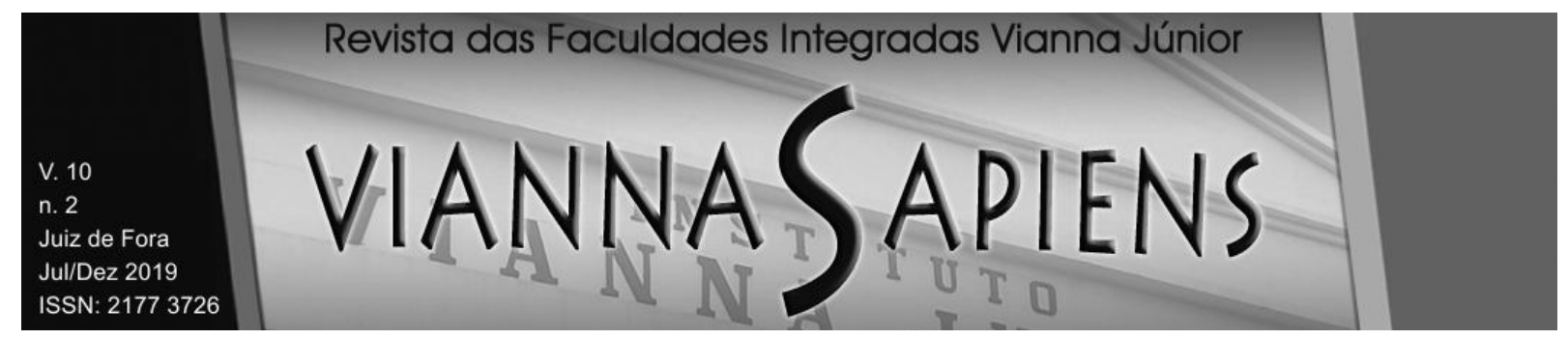

\title{
A tecnologia gerando novos arranjos organizacionais:
}

Análise do modelo DAO sob a ótica da sociomaterialidade

DOI: 10.31994/rvs.v10i2.611

\author{
Francis Berenger ${ }^{1}$ \\ Marcia Penna ${ }^{2}$ \\ Sandra Regina da Rocha-Pinto ${ }^{3}$ \\ Leonardo Lima Gomes ${ }^{4}$
}

\section{RESUMO}

A transformação digital está redefinindo práticas organizacionais. Novos arranjos organizacionais produzem fenômenos inéditos que necessitam ser compreendidos. O objetivo deste trabalho é explorar os fenômenos existentes na DAO (Decentralized Autonomous Organization), modelo organizacional autônomo e descentralizado, construído com base em smart contracts, softwares executados em uma rede peerto-peer com uso da tecnologia de blockchain e que incorpora regras de governança e de tomada de decisão. Utiliza-se a sociomaterialidade como a lente teórica para a condução desta reflexão que permite compreender esse novo arranjo organizacional. $\mathrm{O}$ artigo procura responder à seguinte pergunta de pesquisa: Quais fenômenos organizacionais podem ser identificados no modelo DAO sob a ótica da sociomaterialidade? A pesquisa bibliográfica foi o meio definido para a investigação

\footnotetext{
${ }^{1}$ Professor da Pontifícia Universidade Católica do Rio de Janeiro - Rio de Janeiro - RJ, Brasil; berenger@puc-rio.br; ORCID ID 0000-0002-6727-5805

${ }_{2}^{2}$ Mestranda em Administração da Pontifícia Universidade Católica do Rio de Janeiro - Rio de Janeiro

- RJ, Brasil; marcia.f@mst.iag.puc-rio.br; ORCID ID 0000-0002-4724-4411

${ }^{3}$ Professora da Pontifícia Universidade Católica do Rio de Janeiro - Rio de Janeiro - RJ, Brasil; sanpin@iag.puc-rio.br; ORCID ID 0000-0002-5121-4231

${ }^{4}$ Professor da Pontifícia Universidade Católica do Rio de Janeiro - Rio de Janeiro - RJ, Brasil; leonardolima@iag.puc-rio.br; ORCID ID 0000-0002-5239-7834
} 


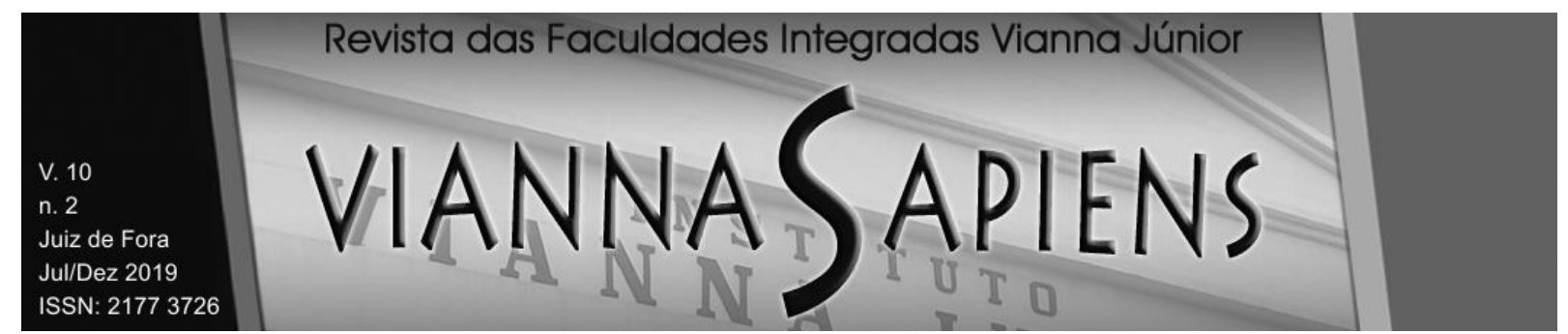

sistematizada, fornecendo material analítico suficiente para a análise e resposta à pergunta proposta. Este ensaio apresenta reflexões acerca da materialidade e centralidade do principal artefato tecnológico do modelo, enfatizando a dualidade da estrutura e agência na DAO. Ao final, sugere-se o aprofundamento no estudo desses novos modelos organizacionais sob a ótica da sociomaterialidade, buscandose na investigação teórica e empírica, a identificação de fenômenos ainda inéditos.

\title{
PALAVRAS-CHAVE: SOCIOMATERIALIDADE. DAO. SMART CONTRACT. ARTEFATO. BLOCKCHAIN.
}

\section{The technology generating new organizational arrangements: the DAO model analysis from a sociomateriality perspective}

\begin{abstract}
Digital transformation is redefining organizational practices. New organizational arrangements produce new phenomena that need to be understood. The objective of this paper is to explore the phenomena that exist in the DAO (Decentralized Autonomous Organization), an autonomous and decentralized organizational model built based on smart contracts, software running on a peer-to-peer network using blockchain technology that incorporates governance and decision-making rules. Sociomateriality is used as the theoretical lens for conducting this reflection that allows us to understand this new organizational arrangement. The article seeks to answer the following research question: What organizational phenomena can be identified in the DAO model from a sociomateriality perspective? Bibliographic research was the defined means for systematized research, providing enough analytical material for the analysis and answer to the proposed question. This essay
\end{abstract}




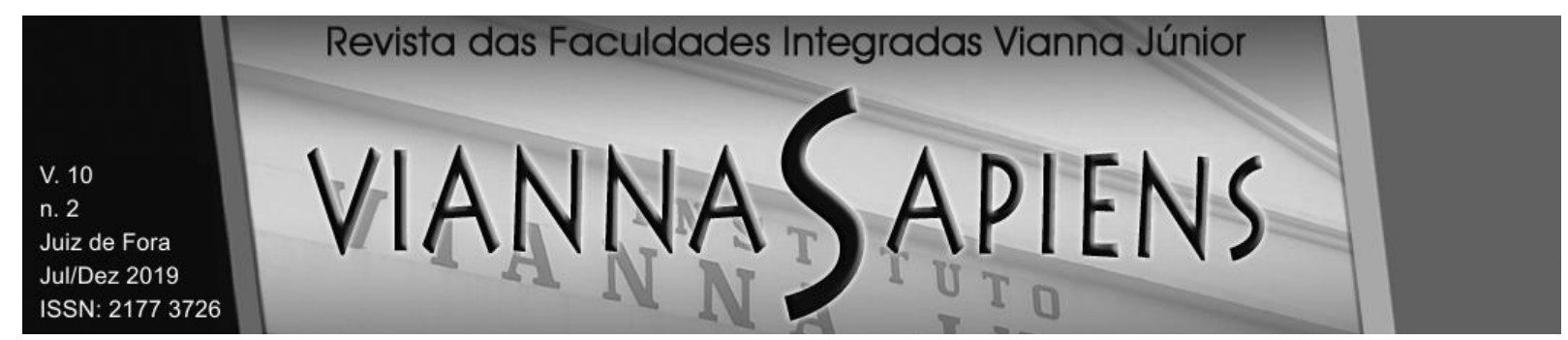

presents conclusions about the materiality and centrality of main technological artifact of the model, emphasizing the duality of structure and agency in DAO. At the end, it is suggested to deepen the study of these new organizational models from the perspective of sociomateriality, seeking in the theoretical and empirical investigation, the identification of phenomena still unknown.

\title{
KEYWORDS: SOCIOMATERIALITY. DAO. SMART CONTRACT. ARTIFACT. BLOCKCHAIN.
}

\author{
INTRODUÇÃO \\ "As coisas que fizemos fazem a gente." \\ Stephen L. Talbott, cientista da evolução
}

A transformação digital está redefinindo práticas organizacionais. Inteligência artificial, data analytics, internet das coisas e blockchain são algumas das tecnologias emergentes que vêm possibilitando as empresas melhorar suas cadeias de valor. Como consequência, os processos de negócio são continuamente modificados pela tecnologia digital que permeia o tecido organizacional. Neste cenário contemporâneo, o estudo investigativo da influência das novas tecnologias nas empresas ganha relevância. Novos arranjos organizacionais produzem fenômenos inéditos que necessitam ser explorados (YOO et al., 2012; ORLIKOWSKI e SCOTT, 2016).

Ao longo do tempo, estudos sobre novas tecnologias vêm contribuindo para a evolução da teoria das organizações. A tecnologia exerce um papel dinâmico de agente modificador das formas, funções e processos organizacionais (ZAMMUTO et al., 2007; LEONARDI e BARLEY 2010). O impacto transformador da tecnologia leva a novas questões relacionadas ao papel do humano e não-humano, organização e artefatos, ação e efeito, convidando assim, ao desenvolvimento de uma análise 


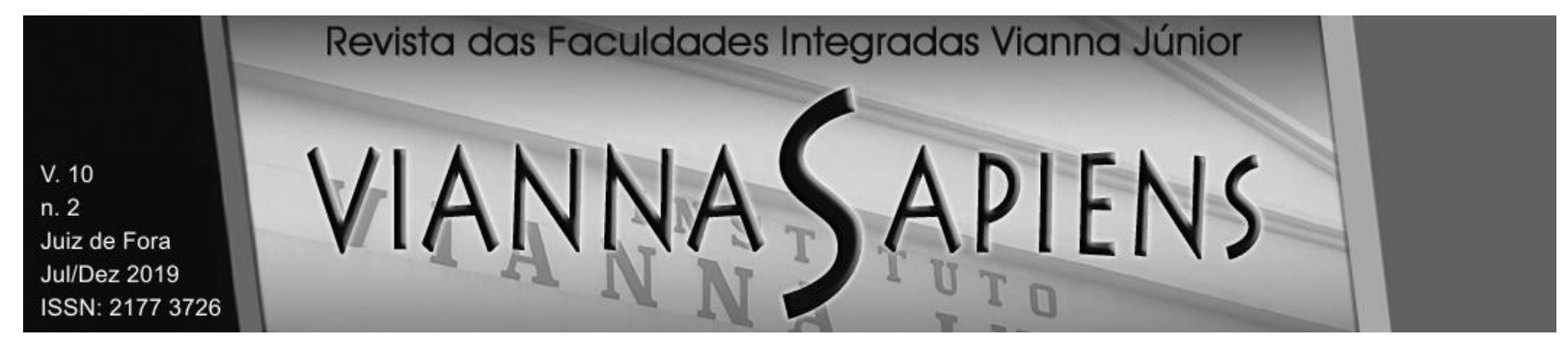

relacional, performativa, comunicativa e sociomaterial (LEONARDI e BARLEY, 2010; ORLIKOWSKI e SCOTT, 2014; KUHN et al. 2017).

Nesse contexto, esta pesquisa foi estruturada a partir de algumas questões orientativas relativas às implicações das tecnologias emergentes nas organizações, a saber: Como tecnologias emergentes reconfiguram os arranjos organizacionais? Quais diferentes fenômenos são identificados nesses novos modelos? Como repensar questões relacionadas à agência humana e material em um contexto social criado a partir da relação com os novos artefatos tecnológicos? Delimitou-se, por conseguinte, explorar essas questões sob o viés da sociomaterialidade, considerando a relevância dessa abordagem nos estudos organizacionais recentes (ORLIKOWSKI, 2000, 2007; LEONARDI, 2010, 2011; DAMERON, LÊ e LE BARON, 2015). Sociomaterialidade é a fusão das palavras 'social' e 'material' representando o entrelaçamento constitutivo do social humano com a materialidade dos artefatos presentes no cotidiano organizacional (ORLIKOWSKI, 2000).

O presente trabalho é um ensaio-teórico que investiga as relações sociais e materiais das práticas organizacionais presentes no modelo DAO (Decentralized Autonomous Organization). Esse modelo organizacional autônomo e descentralizado é construído com base em smart contracts ${ }^{5}$, softwares executados em uma rede peer-to-peer $r^{6}$ com uso da tecnologia de blockchain e que incorpora regras de governança e de tomada de decisão. O smart contract é programado para operar sem que haja envolvimento humano na sua gerência, de forma que o controle é realizado exclusivamente pelo código. Busca-se nesse modelo implantar certos aspectos da governança tradicional, substituindo-se a execução voluntária de ações de compliance por um código computacional com funções consensualmente acordadas previamente (KATENDE e DUBE, 2018).

O objetivo deste trabalho é explorar novos fenômenos existentes em arranjos organizacionais gerados por tecnologias emergentes. O modelo DAO é o espaço de pesquisa definido por ser recente e ainda pouco explorado. Utiliza-se a

\footnotetext{
${ }^{5}$ Softwares destinados a impor digitalmente a execução de um contrato.

${ }^{6}$ Arquitetura de rede computacional que permite conectar dois nós diretamente.
} 


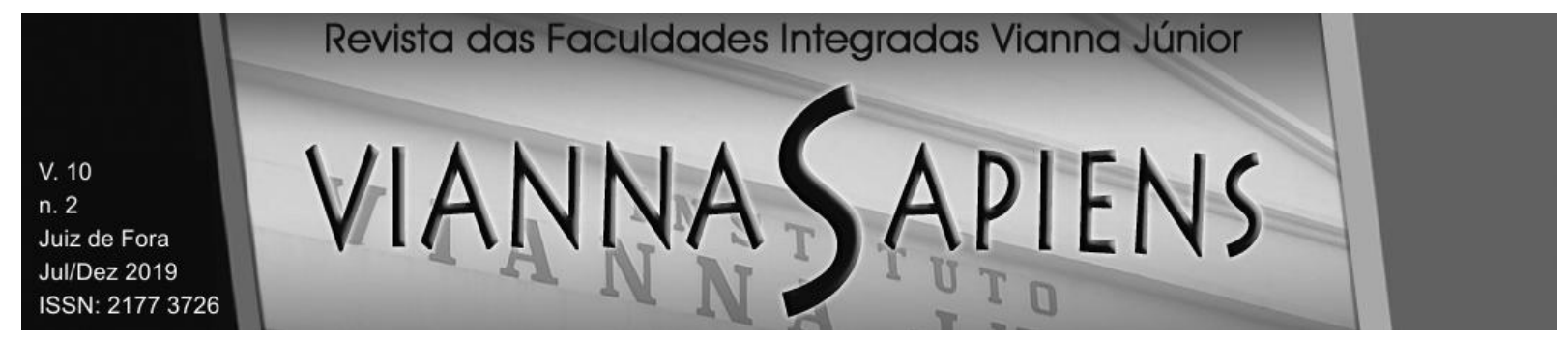

sociomaterialidade como a lente teórica para a condução da análise, na qual se discute a constituição do modelo, suas práticas organizacionais e a relação entre agência humana e agência material dos artefatos tecnológicos. A pesquisa bibliográfica foi o meio definido para a investigação sistematizada, fornecendo material analítico suficiente para a análise e reflexão. A natureza interpretativa e reflexiva deste ensaio explora os fenômenos organizacionais com base no recorte definido nesta pesquisa. Diante do exposto, o presente ensaio almejou responder a seguinte pergunta de pesquisa: Quais fenômenos organizacionais podem ser identificados no modelo DAO sob a ótica da sociomaterialidade?

Este artigo traz, inicialmente, uma revisão da literatura sobre a sociomaterialidade. Em seguida, apresentam-se a metodologia utilizada no ensaio, o espaço de pesquisa definido e as reflexões provenientes da análise do modelo DAO sob a ótica da sociomaterialidade. Ao final, apresentam-se conclusões acerca da materialidade e centralidade do principal artefato tecnológico do modelo, enfatizando a dualidade da estrutura e agência na DAO.

\section{REFERENCIAL TEÓRICO}

\subsection{Sociomaterialidade}

Investigar a influência da tecnologia nas organizações exige entender em como práticas organizacionais relacionam-se com os artefatos tecnológicos a partir de uma análise sociomaterial. O termo sociomaterialidade indica que o social e o material são inseparáveis e indissociáveis, na medida em que toda a materialidade é social, sendo criada, interpretada e usada em um contexto social (LEONARDI, 2012; ORLIKOWSKI e SCOTT, 2016). Nesse sentido, o estudo da sociomaterialidade exige que os aspectos relativos à materialidade dos artefartos sejam estudados para o melhor entendimento do fenômeno social. 


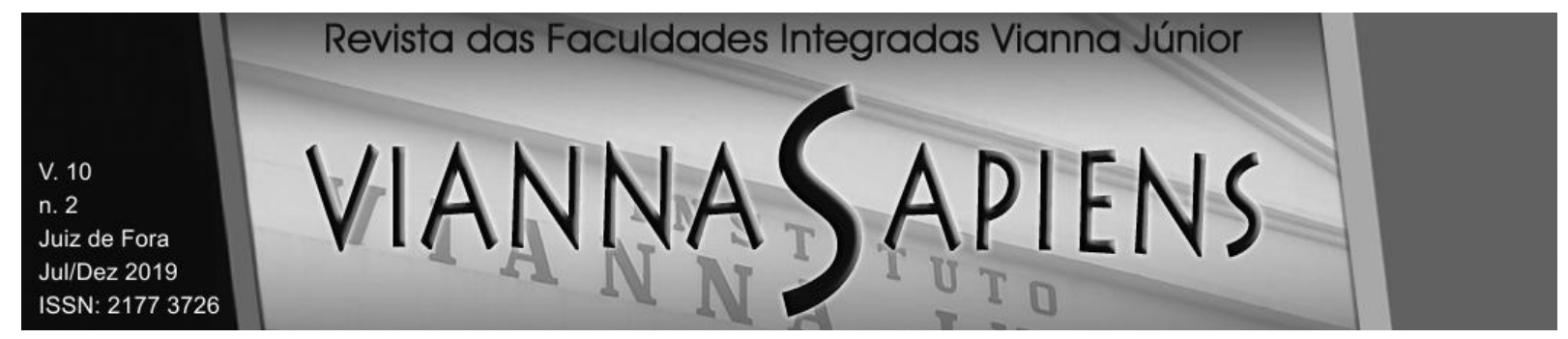

Artefatos tecnológicos podem ser físicos e não físicos. Artefatos físicos são mais evidentes como um teclado, uma placa de computador ou um monitor. Já os artefatos tecnológicos não físicos são caracterizados por sua intangibilidade como no caso de um software ou de uma rede de computadores. Diferentemente do senso comum, o conceito de materialidade nos artefatos tecnológicos não se associa apenas aos seus aspectos físicos, estando também presente nos artefatos não físicos (SUCHMAN, 2000; ORLIKOWSKI, 2007).

A materialidade do artefato tecnológico "refere-se a maneira pela qual as matérias físicas e/ou digitais são organizadas em formas particulares que perduram independentemente do tempo e espaço" (LEONARDI, 2012, p. 29). No caso de um artefato tecnológico não físico, como um software, a materialidade encontra-se em como o seu código está organizado. A matéria digital é constituída a partir da construção de algoritmos com propósitos específicos para prover funcionalidades para os usuários. Em resumo, a materialidade de um software é composta pela matéria (código digital) e forma (como as funcionalidades do código são disponibilizadas para o usuário) que se mantém invariável ao longo do tempo a partir de um mesmo conjunto de funcionalidades oferecidas. Uma versão específica de um software possui um conjunto limitado e invariável de funcionalidades até que essa mesma matéria digital seja modificada gerando, então, um novo artefato (nova versão do software).

Quando uma empresa adquire determinada versão do Microsoft Excel, as funcionalidades constituintes da materialidade do software são invariáveis, contudo, o uso do software varia em função do contexto e propósito para o qual está sendo usado. Nesta situação, observa-se que a materialidade do software existe independentemente das pessoas, contudo, são as pessoas que dão sentido prático ao uso do software.

A tecnologia pode evoluir ao longo do tempo, consequentemente, a materialidade de artefatos tecnológicos sofre modificações em decorrência de alterações de matéria e forma. Como exemplo, a materialidade do Microsoft Excel 2010 é muito diferente da versão inicial do software lançada em 1987. Usuários 


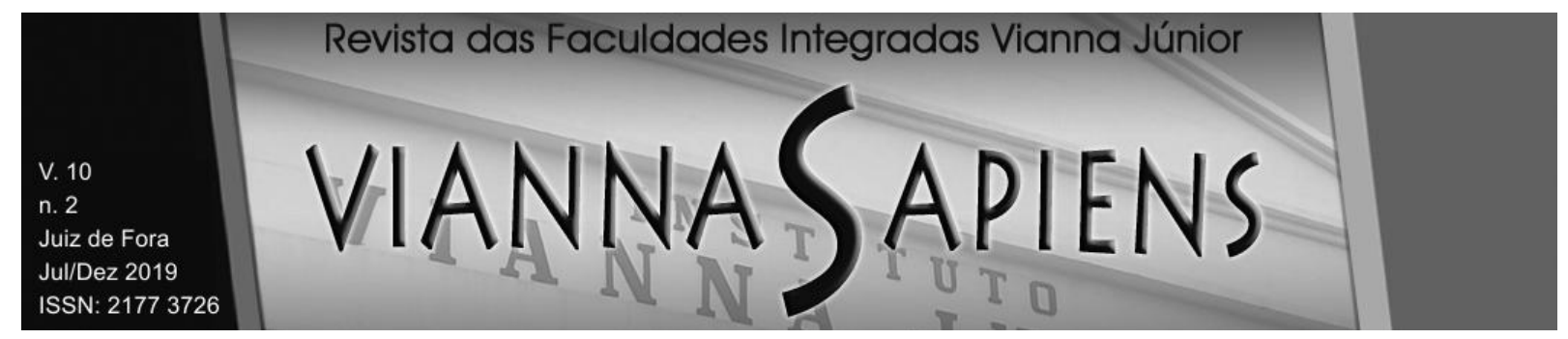

compram novas versões de software e realizam upgrades com interesse nessas novas materialidades (LEONARDI et al., 2012).

A materialidade dos artefatos pode ser percebida de uma maneira particular por uma propriedade conhecida como affordance, que se refere ao potencial de uso do artefato conforme projetado. Cacciatori (2012) expõe que o formato dos artefatos disponibiliza conhecimento sobre como determinada tarefa deve ser realizada. Percebe-se o affordance no entendimento intuitivo de que chaves foram feitas para girar e alavancas para serem puxadas. Callon e Muniesa (2005) apresentam o artefato não como um guia passivo e estruturante que leva o sujeito a realizar uma ação, mas como uma construção que convida o sujeito à realização da ação.

A propriedade do affordance é também manifestada em artefatos tecnológicos não físicos, como, por exemplo, na interface gráfica de um software que permite que o usuário intuitivamente saiba como interagir com o programa, mesmo sem nunca o ter usado. Tecnologias que transformam informação não apenas oferecem affordance que mudam as práticas do trabalho, como frequentemente mudam a própria natureza do trabalho (LEONARDI, 2010).

Enquanto a materialidade indica as propriedades de um artefato, a sociomaterialidade representa a maneira com que as atividades integram a materialidade com normas corporativas e institucionais. Parte-se da materialidade dos artefatos para entender o seu relacionamento com os aspectos sociais. Não há social que também não seja material, e não há material que não seja também social (ORLIKOWSKI, 2007). A sociomaterialidade dos artefatos tecnológicos não está centrada na tecnologia, mas, sim, na prática na qual a tecnologia está inserida. Prática é um espaço social compartilhado por uma comunidade, no qual se desenvolve uma lógica situacional em que os atores envolvidos reconhecem, produzem e formulam as cenas e regulam os negócios do dia a dia (LAVE, 1988; GHERARDI, 2011). 


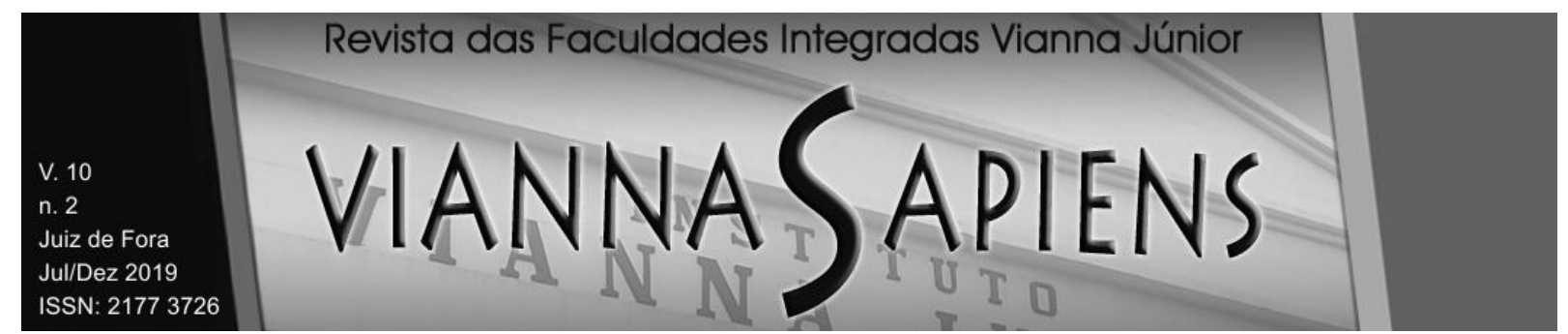

\subsection{Agência Humana e Agência Material}

A agência humana (social) e a agência material (artefatos) se manifestam no espaço social influenciando a dinâmica das práticas sociais. A agência humana envolve a capacidade de 0 ator pensar e agir a partir de padrões conhecidos, contudo há a possibilidade da sua capacidade imaginativa reconfigurar estruturas de pensamentos e ações. Abre-se, dessa forma, opções de alternativas de ações em resposta a demandas emergentes, dilemas e ambiguidades, que $\mathrm{o}$ ator julga $e$ decide pela qual escolherá (EMIRBAYERS e MISCHE, 1998). Já a agência material ou actância representa a influência exercida pelos artefatos nas práticas sociais, restringindo ou habilitando a agência humana em situações específicas. Leonardi (2011, p. 148) define a agência material como "a capacidade de entidades nãohumanas agirem por conta própria, além da intervenção humana".

Agentes humanos envolvidos na execução de práticas organizacionais são, por muitas vezes, obrigados a interagir com artefatos que diretamente exercem uma influência nos aspectos performativos. A partir dessa visão, artefatos podem ser vistos como influenciadores na persistência de padrões existentes ou na emergência de novos padrões (D'ADDERIO, 2011). A agência humana é exercida em resposta a uma agência material do artefato (JONES, 1998), de forma que não há como se obter previsibidade total sobre o resultado desse relacionamento. Pessoas agem de acordo com seus interesses e orientações afetivas, fazendo uso dos artefatos tecnológicos a partir de objetivos próprios. Nesse sentido, as atividades de uma pessoa não são determinadas prescritivamente pela tecnologia por ela empregada. A relação entre o social humano e o material artefatual é complexa e envolve situações contingenciais no tempo e espaço.

Artefatos tecnológicos não físicos são construções humanas que podem incorporar um determinado conjunto de ações em scripts embarcados, assumindo um papel de mediação em práticas organizacionais. A criação de scripts envolve um processo chamado inscription na qual "atores delegam conhecimento e objetivos ao artefato durante seu design e uso" (D’ADDERIO, 2014, p. 1343). Como exemplo de 


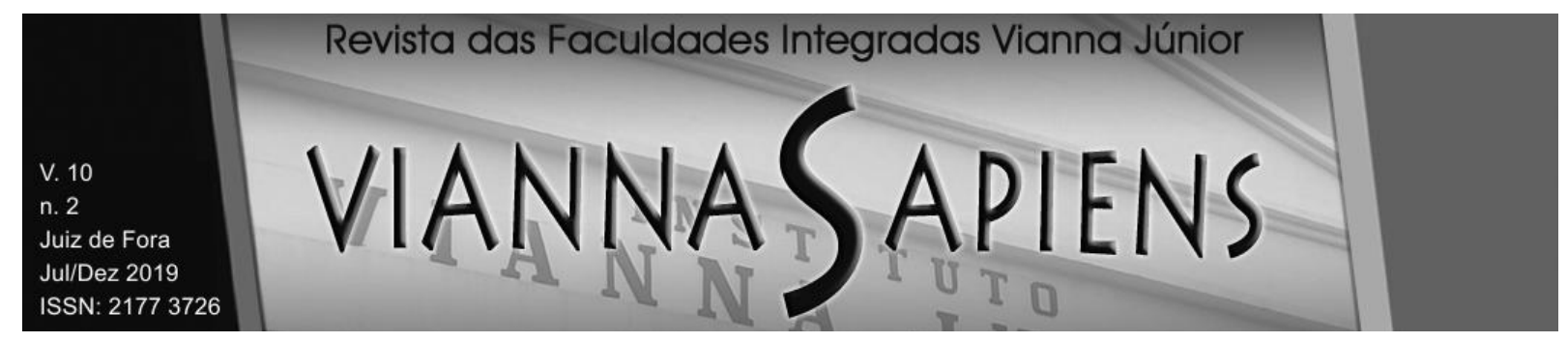

inscription, é possível considerar o momento do desenvolvimento de um software, na qual o projetista define premissas, restrições e formas de interação que influenciarão os usuários dentro de um contexto social o qual o software será utilizado.

O fenômeno da sociomaterialidade é percebido quando observamos que artefatos tecnológicos atuam como mediadores que "realizam ou influenciam as práticas nas quais estão envolvidos e os contextos nos quais estão inseridos" (D'ADDERIO, 2011, p. 212). Define-se nesse contexto o conceito de rotinas artefactuais nas quais um artefato possui forte actância sobre os agentes humanos, a partir do processo de inscription realizado na sua construção.

A sociomaterialidade também se faz presente na recursividade existente entre as agências humana e material, impactando nos aspectos performativos das práticas organizacionais, assim como na constituição e mudança da própria tecnologia. Leonardi (2011) conceitua essa relação entre as agências humana e material como imbricamento, fator de flexibilização tanto para uma rotina organizacional quanto para $\mathrm{o}$ artefato. $\mathrm{Na}$ concepção original da palavra, imbricamento refere-se à sobreposição de elementos independentes que são fortemente ligados, semelhantes ao arranjo entre as telhas existente em telhados de casas. Taylor et al. (2007) também utilizam o conceito de imbricamento para representar o entrelaçamento das relações interagências na constituição da infraestrutura organizacional.

O resultado do imbricamento entre agência humana e material se faz presente quando se observam as rotinas organizacionais como uma estrutura dinâmica e generativa. A interação entre artefatos e agência é parte do mecanismo interno das rotinas organizacionais (FELDMAN e PENTLAND, 2003). Atores humanos conferem significados aos artefatos que, por sua vez, possuem um papel determinante para as rotinas organizacionais. Um artefato pode interferir na rotina de modo a solidificar um determinado padrão de ação ou fazer variar o curso da sua ação. Agentes envolvidos na execução das rotinas são, por muitas vezes, obrigados a interagir com artefatos que diretamente exercem uma influência nos aspectos performativos. A partir dessa visão, artefatos podem ser vistos como influenciadores 


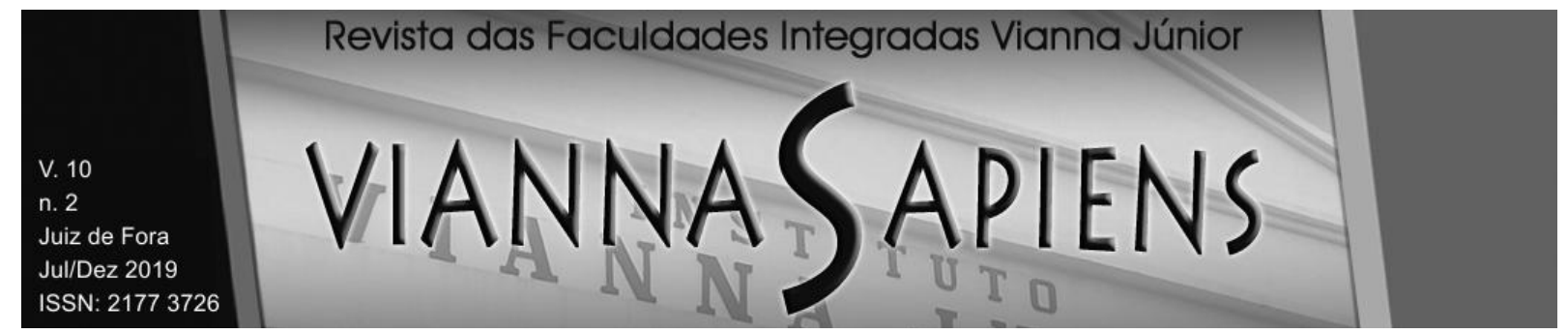

na persistência de padrões existentes ou na emergência de novos padrões (D’ADDERIO, 2011). Esta perspectiva ilustra também um aspecto dinâmico da sociomaterialidade gerado a partir do imbricamento entre as agências humana e material.

\section{METODOLOGIA}

Este ensaio-teórico apresenta análises e reflexões sobre o modelo DAO para explorar fenômenos inéditos sob a ótica da sociomaterialidade. Não é objetivo deste artigo esgotar o assunto, mas apresentar, na visão dos autores, críticas e ideias sobre o tema tratado. Um ensaio caracteriza-se pela sua natureza reflexiva e interpretativa, sem a necessidade de provas empíricas ou dedutivas de caráter científico (MENEGHETTI, 2011).

Esta pesquisa é classificada como exploratória, na medida em que há pouco conhecimento acumulado e sistematizado sobre o modelo estudado, como também descritiva, pois expõe características de um determinado fenômeno sem 0 compromisso de explicá-lo (VERGARA, 2016).

Para a composição do referencial teórico, uma pesquisa bibliográfica foi realizada a partir de uma revisão sistemática de artigos relacionados ao tema da sociomaterialidade. Buscou-se com isso, identificar aspectos teóricos sobre a relação social e material de artefatos tecnológicos que possibilitasse fomentar a reflexão a respeito do modelo estudado. Nessa pesquisa, destacaram-se as produções dos autores Leonardi (2010, 2011, 2012, 2013) e Orlikowski (2000, 2007, 2016).

O modelo DAO compõe o espaço de pesquisa deste ensaio, a partir do qual a análise e reflexão é realizada com o propósito de ajudar a construção do conhecimento. $\mathrm{Na}$ composição deste espaço, uma pesquisa bibliográfica foi realizada, contudo não revelou extensas publicações acadêmicas, indicando o quanto o tema é emergente e apresenta um campo empírico em construção. Para 


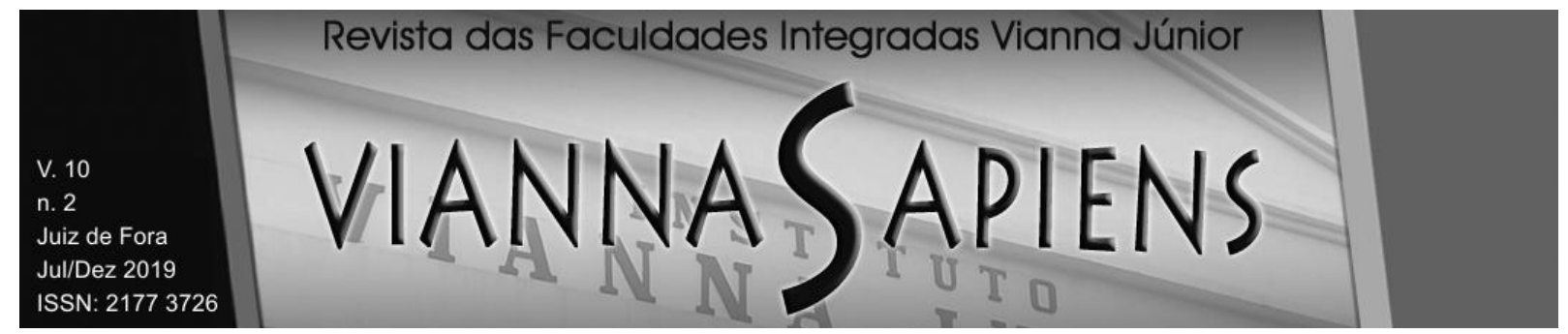

preencher esta lacuna, buscou-se informações em white papers e artigos na internet.

\section{ESPAÇO DE PESQUISA}

Para o entendimento do espaço de pesquisa, o modelo DAO (Decentralized Autonomous Organization) é apresentado detalhadamente, incluindo fundamentos, o artefato tecnológico smart contract e os mecanismos de consenso do modelo. Ao final, apresenta-se o caso The DAO por ter sido um marco relevante no estudo de modelos organizacionais autônomos.

\subsection{O modelo DAO}

A DAO é um modelo organizacional autônomo e descentralizado. Seus fundamentos foram pensados na década de 1990 por Nick Szabo, jurista e cientista da computação, que criou a expressão smart contracts (contratos inteligentes) para indicar um conjunto de práticas evoluídas da lei e de relacionamentos contratuais entre usuários de uma rede de computadores. Os contratos inteligentes caracterizam-se por serem mecanismos de relacionamento entre pessoas que dispensam a necessidade de confiança mútua entre as partes envolvidas ou no sistema jurídico para julgar eventuais conflitos. É possível exemplificar esse uso em uma comunicação máquina-a-máquina no qual um veículo pode 'conversar' com um posto de pedágio negociando a tarifa em função de um contrato pré-existente entre as partes interessadas, sem que haja intervenção humana (HANADA, HSIAO e LEVIS, 2018). 


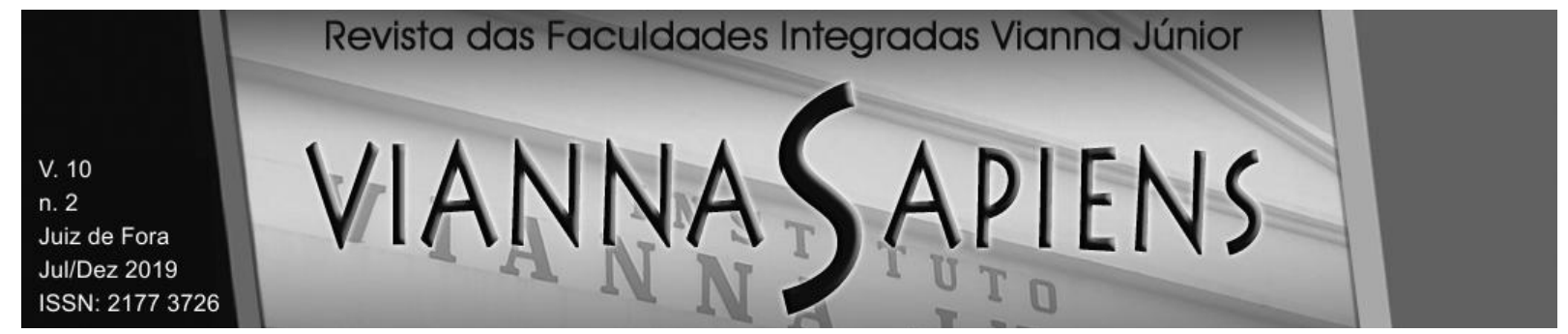

\subsection{Smart Contracts}

Os smart contracts são implementados por intermédio de softwares desenvolvidos com esse propósito e codificados a partir da definição prévia de um modelo de governança, acordado entre os membros da DAO. Esses contratos inteligentes são autoexecutáveis, regidos apenas por software no controle das ações dos usuários, objetivando a não ocorrência de impasses, conflitos e fraudes entre seus membros durante a execução das rotinas. Dessa forma, não há necessidade de se apelar para agentes externos arbitrarem eventuais incidentes.

As regras do acordo, descritas no código, devem ser transparentes e imutáveis. Na adoção de smart contracts costuma-se dizer que 'o código é lei', expressão cunhada por Lessig (1999) a respeito do princípio que o código é a lei no cyberspace. Contratos inteligentes são inflexíveis e irreversíveis pois, uma vez assinados, se cumprem de forma automática, completamente alheios aos poderes jurisdicionais tradicionais do Estado (GONÇALVES e CAMARGOS, 2017).

Szabo (1997, p.2) afirma que a ideia dos smart contracts é que "muitos tipos de cláusulas contratuais podem ser embarcados em hardware e software que utilizamos, de forma que a quebra de um contrato teria um alto custo financeiro para o usuário violador". Isso significa que o esforço tecnológico para violar esse contrato, como no caso do uso de um código malicioso, incorreria em determinado custo que não justificaria a ação. Outro exemplo simples de aplicação de smart contract pode ser observado em uma vending machine. Nesse caso, uma pessoa pode comprar uma bebida em uma interação direta com a máquina que detém um produto, estabelece preço, realiza a transação financeira e entrega o produto. $O$ custo de violação da máquina é maior do que o valor do bem nela contido.

Com o advento das tecnologias emergentes, smart contracts têm sido construídos com o uso da tecnologia de blockchain. Essa tecnologia foi popularizada e difundida a partir da criação do Bitcoin com adoção subsequente na construção de outras criptomoedas. O blockchain é essencialmente um banco de dados distribuído composto por uma cadeia sequencial de blocos encadeados. Todos os dados 


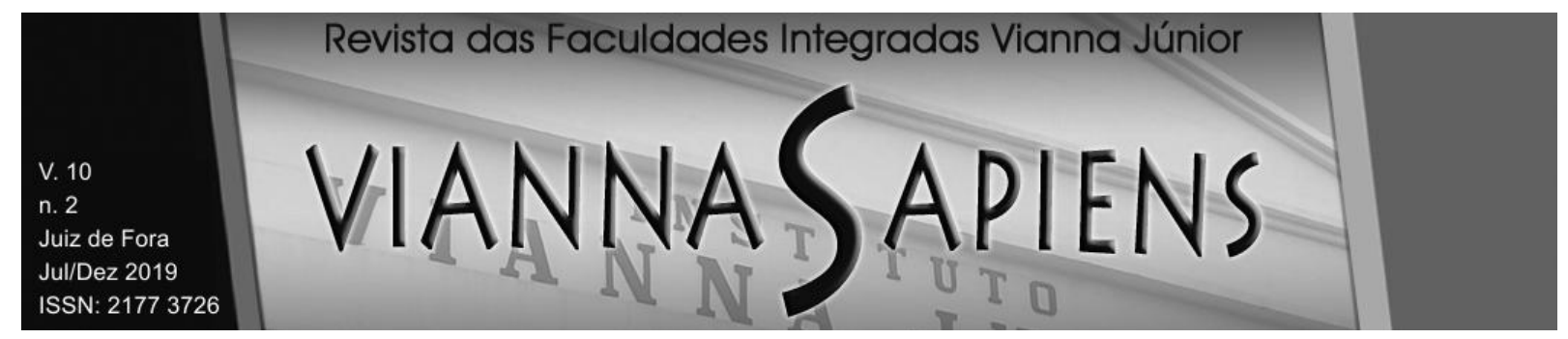

gravados nos blocos da cadeia são armazenados perpetuamente, não existindo a possibilidade de alteração ou eliminação de um bloco da estrutura. A cadeia de blocos é compartilhada por inúmeros nós em uma rede computacional descentralizada. Essa arquitetura distribuída garante a alta disponibilidade de acesso aos dados, pois mesmo que haja indisponibilidade de um ou mais nós da rede, os blocos estarão sempre disponíveis por estarem replicados em inúmeros outros nós. Outra característica dessa tecnologia é a transparência total do conteúdo dos dados da estrutura, possibilitando que seja sempre possível o acesso de leitura ao conteúdo da cadeia de blocos. A tecnologia do blockchain garante que os dados da cadeia sejam imutáveis, permanentes e públicos (NAKAMOTO, 2008). A figura 1 ilustra simbolicamente a arquitetura da DAO, incluindo as camadas do smart contract e o blockchain.

Figura 1 - Arquitetura da DAO

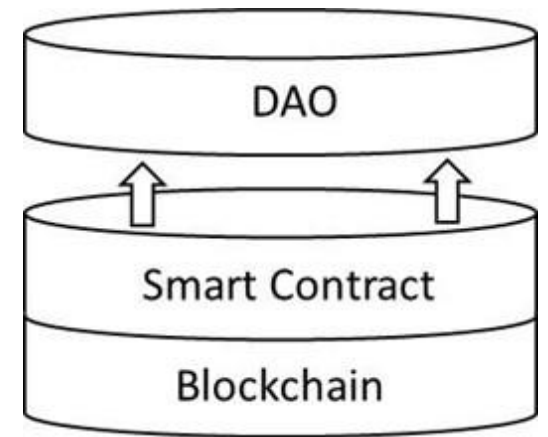

Fonte: autores

A implantação de smart contracts, a partir da tecnologia de blockchain, possui diversas vantagens. A gravação de contratos implementados por algoritmos em códigos armazenados nos blocos da cadeia garante a perpetuidade e a transparência do acordo entre as partes. A natureza irretroativa do blockchain impede que as regras sejam alteradas em benefício de qualquer pessoa. Gonçalves e Camargo (2016, p. 209) comentam que "no âmbito dos smart contracts, sua eficácia depende apenas do cumprimento de requisitos objetivos de possibilidade, 


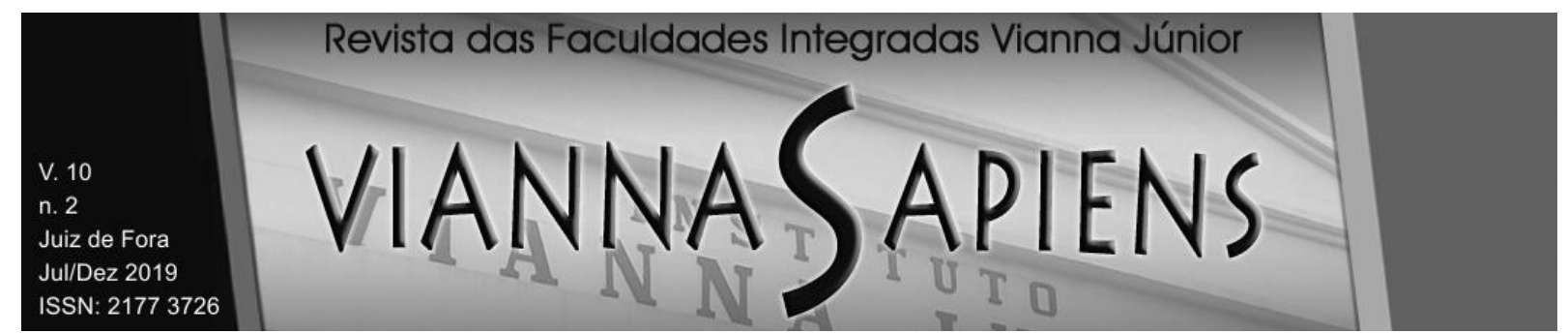

determinação e economicidade". Dessa forma, não há relevância prática e factual para argumentações subjetivas questionando a validade das regras dos contratos.

\subsection{Mecanismos de Consenso de um Modelo DAO}

Um smart contract, quando criado, tem seu código gravado na blockchain. A partir do momento que a execução do código é iniciada, o modelo DAO começa a ser constituído com adesões de membros e interação de usuários estabelecendo-se, dessa forma, uma organização autônoma e descentralizada com funcionamento ininterrupto. Por ser um software autônomo, o código do smart contract é imutável, não podendo ser modificado por nenhuma pessoa, nem mesmo por seu criador. As organizações autônomas são implementadas considerando-se mecanismos de consenso que possibilitam aos seus membros tomarem decisões. Regras de votação dentro da organização são definidas e implantadas nos contratos a partir do modelo de governança estabelecido para se chegar a decisões organizacionais.

Jentzsch (2016) alerta para um problema existente com membros minoritários de uma organização e que deve ser evitado no mecanismo de consenso definido. Membros com maioria no sistema de votos podem alterar o modelo de governança da organização após a formação da DAO de forma a obter benefícios sobre os membros minoritários. Essa é uma situação que, muitas vezes, pode ser indesejada e que para ser evitada deve haver impedimentos a partir das regras definidas. Uma das maneiras de evitar esse tipo de situação é possibilitar que membros minoritários possam recuperar seus fundos. Esse procedimento pode ser feito com a possibilidade do modelo DAO se dividir em dois a partir da insatisfação de alguns membros. Para isso, deve haver a submissão de uma proposta especial executada por um dos membros para que seja criada uma nova DAO. Em caso de aprovação, os membros que votaram a favor da divisão migram para a nova organização e o impasse é resolvido. Um modelo robusto de organização deve garantir que não haja conluios entre pessoas desonestas ou invasores que utilizam códigos maliciosos. 


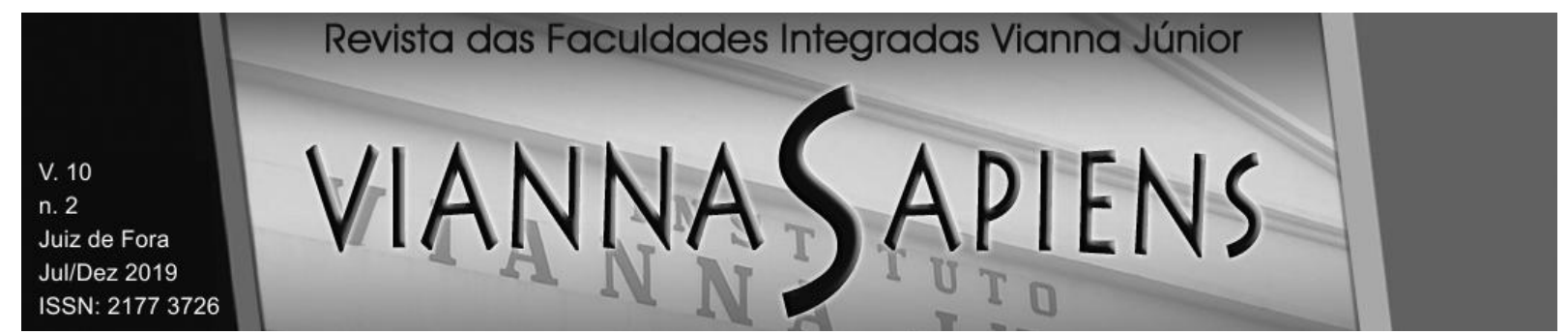

\subsection{0 caso The DAO}

Das implementações de modelos DAO já realizadas, a que teve maior projeção chama-se The DAO. Essa organização autônoma foi criada como um fundo de risco formado por uma comunidade descentralizada de investidores que decidiam por votos quais projetos receberiam investimentos em criptomoeda da blockchain Ethereum. $O$ objetivo era financiar startups que trabalhassem com tecnologia de blockchain. Uma startup poderia solicitar um aporte financeiro e tendo o projeto aprovado pelos membros da organização, receberia o montante em criptomoeda a partir da adesão ao smart contract da The DAO. Todas as informações sobre o pedido de financiamento, aprovação e investimento ficariam registradas publicamente na blockchain.

O modelo The DAO teve como objetivo captar recursos financeiros dos investidores interessados em fazer parte da organização durante o período de abril a maio de 2016. Ao final, mais de 10.000 pessoas tinham investido o equivalente a cerca de US\$250 milhões. Foi a maior arrecadação realizada de crowdfunding até aquela data (DUPONT, 2017). Pouco tempo depois, uma falha no código do smart contract foi explorada e um desconhecido conseguiu transferir cerca de US $\$ 56$ milhões para sua conta pessoal. Essa situação crítica gerou uma intervenção não prevista no modelo DAO, impedindo que o valor desviado em criptomoeda pudesse ser trocado pelo invasor por alguma moeda conversível. Houve, nesse caso, um desrespeito ao princípio da imutabilidade dos blocos do blockchain. Posteriormente, uma solução definitiva, conhecida como hard fork, foi adotada. Blocos com informações indesejadas da blockchain Ethereum foram desconsiderados e um novo contrato foi criado permitindo que os investidores retirassem todos seus investimentos do contrato anterior. Essa decisão fez com que as regras originais do smart contract fossem 'quebradas' e a The DAO foi definitivamente apagada da blockchain (DUPONT, 2017).

As intervenções realizadas no caso The DAO na blockchain Ethereum foram bastante polêmicas. Alguns grupos argumentaram que a realização de um hard fork 


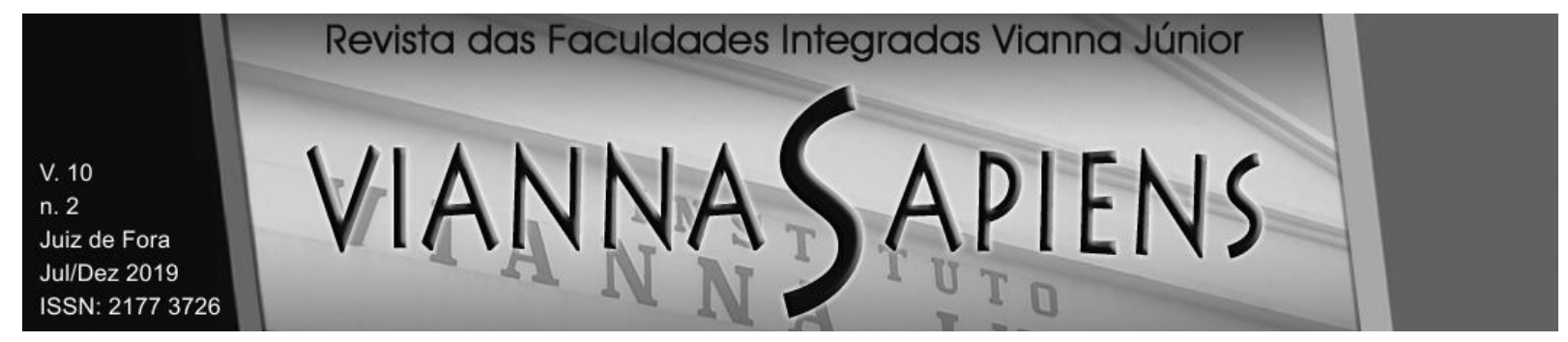

foi um ato autoritário que feriu o princípio democrático de uma DAO. Se o 'código é lei', o invasor apenas explorou uma falha no código do contrato. Partindo desse princípio, qualquer tipo de bloqueio na ação realizada estaria indo contra o espírito de uma organização autônoma descentralizada. Quanto às possíveis perdas financeiras que poderiam ter ocorrido, pode-se considerar que os membros da DAO aceitaram voluntariamente associar-se à organização concordando com o contrato proposto, o que incluiria possíveis falhas existentes no código do contrato.

O caso The DAO é um marco relevante no estudo de modelos organizacionais diante do ineditismo da proposta e do grande interesse despertado por investidores que aportaram capital significativo em uma comunidade de pessoas anônimas regidas apenas por um software que automatizava todo relacionamento entre as partes. $O$ insucesso desse primeiro grande experimento tem proporcionado o aprofundamento nos debates sobre o design de uma organização autônoma descentralizada com respectivos ajustes nos mecanismos de implementação. Novos modelos DAO estão sendo criados e vem sendo estudados sob diversos aspectos.

\section{A ANÁLISE DO MODELO DAO SOB A ÓTICA DA SOCIOMATERIALIDADE}

Organizações autônomas são arranjos sociais que produzem fenômenos complexos e dinâmicos com relevância para serem investigados dentro dos estudos organizacionais. A DAO é um exemplo de um novo modelo fundamentado no conceito de uma organização social em que as relações entre os seus membros ocorrem mediadas exclusivamente por robôs e softwares. A partir do objetivo proposto neste ensaio, o modelo DAO foi analisado sob a ótica da sociomaterialidade. Esse modelo organizacional autônomo e distribuído é centrado no artefato tecnológico não físico smart contract, elemento chave que media as interações entre os membros da organização autônoma. A análise realizada parte dessa característica principal para a investigação de aspectos relacionais sociais envolvendo os membros da organização e o artefato smart contract com as 


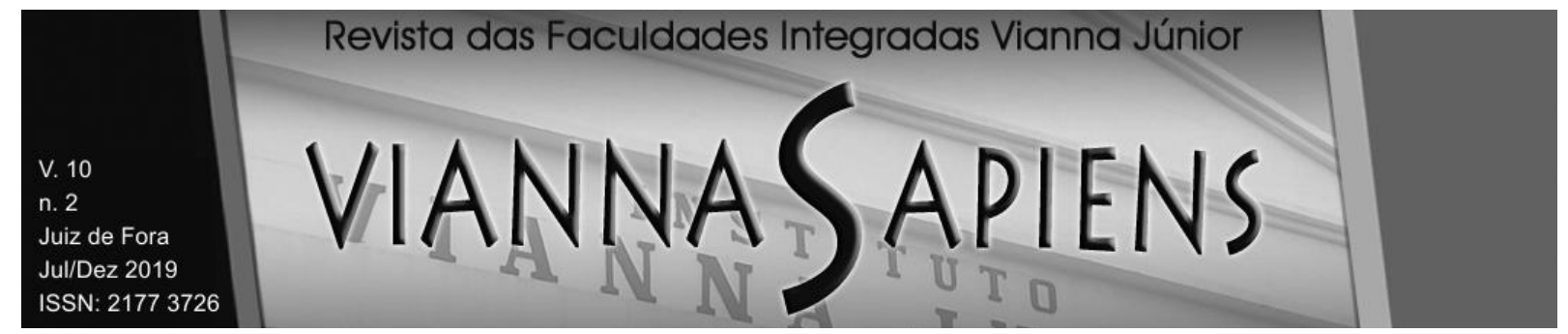

respectivas consequências nas práticas organizacionais. A figura 2 ilustra, simbolicamente, os conceitos da sociomaterialidade analisados no modelo DAO estudado e apresentadados ao longo do artigo.

Figura 2 - Sociomaterialidade na DAO

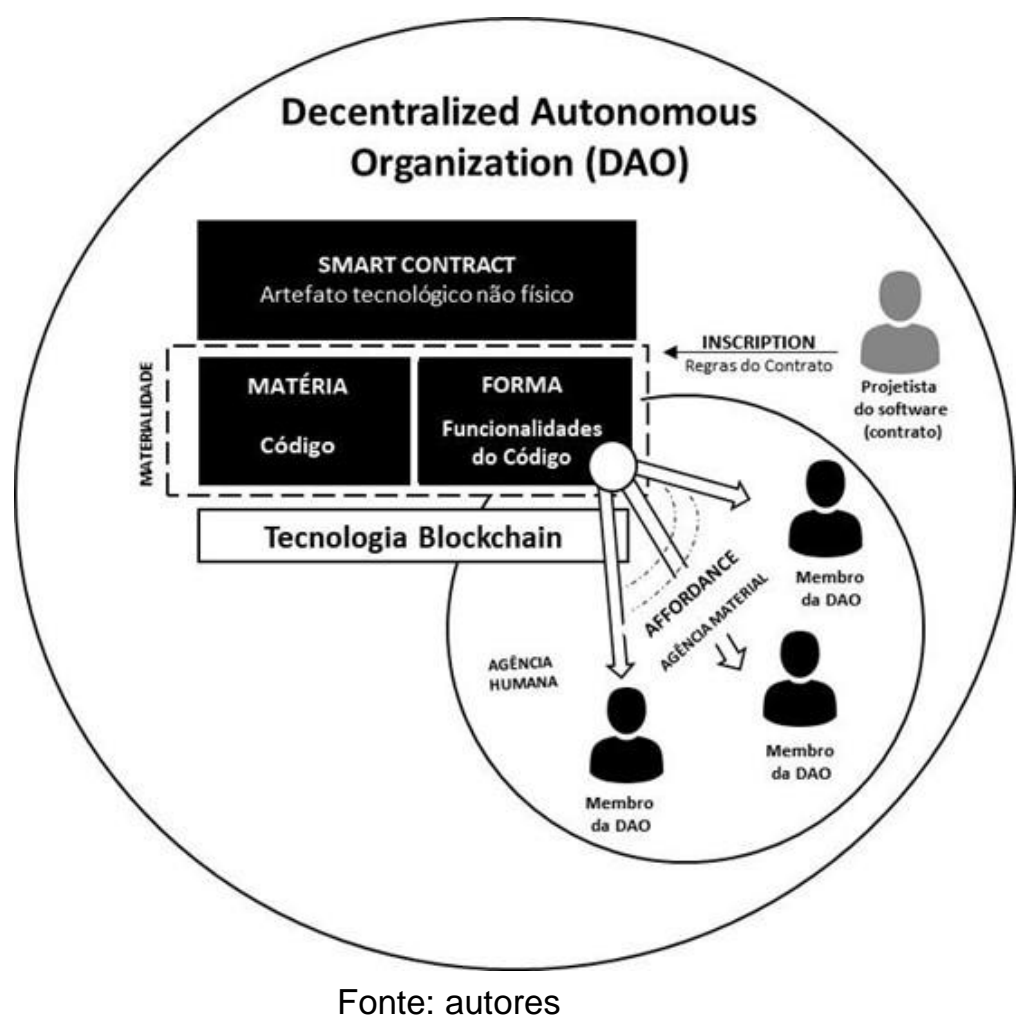

\subsection{Reflexão 1: A materialidade do artefato smart contract no modelo DAO}

Como recorte para uma primeira análise da sociomaterialidade no modelo DAO, a materialidade do artefato smart contract foi explorada a partir do referencial teórico de Leonardi (2010). O autor apresenta a materialidade digital a partir de três conceituações distintas extraídas do Oxford English Dictionary: "materialidade como (1) matéria; (2) instanciamento prático; e (3) significância" (p. 2). Esses conceitos foram utilizados como parâmetros para a análise do caso estudado.

Na primeira conceituação, a materialidade é entendida como a matéria física do artefato. O autor argumenta que a matéria apenas tem importância quando 


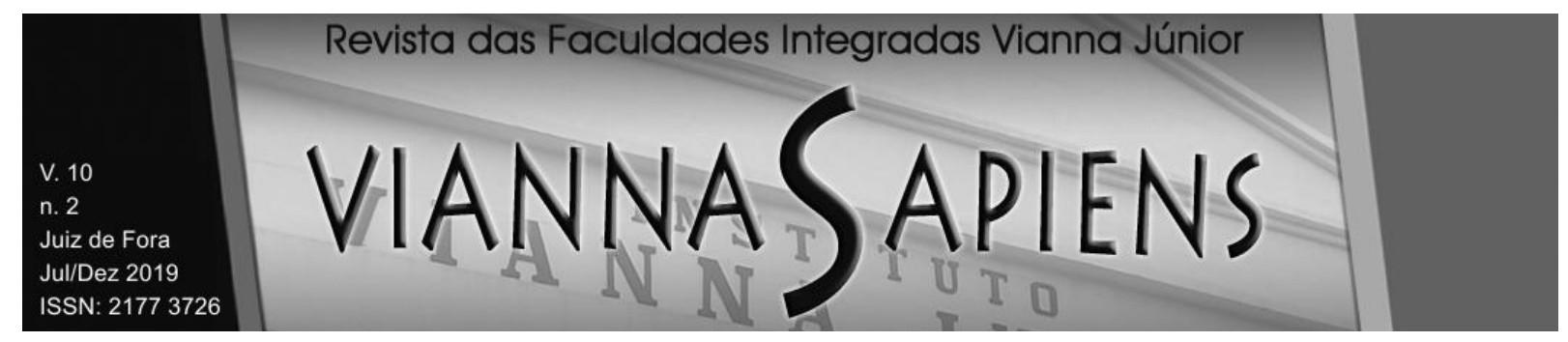

utilizada com algum objetivo específico. Pessoas interagem com artefatos quando existe a necessidade de realizar alguma tarefa. Dessa forma, mais importante que a matéria que constitui o artefato é o 'para que' o artefato foi construído. Esse entendimento remete a propriedade de affordance e de como as pessoas percebem o propósito de um artefato a partir da sua observação. Nesse caso, a propriedade de affordance não é exclusiva do artefato, mas, compreende também o relacionamento entre a materialidade do artefato e as pessoas que o utilizam. No modelo DAO, esse aspecto relacional pode ser notado quando um membro, ao aderir à organização, reconhece as limitações na sua agência impostas pela materialidade imutável do artefato smart contract. O princípio do 'código é lei' e a impossibilidade de existir intermediação por agentes externos à organização é uma condição sine qua non do modelo. O membro da DAO 'assina o contrato' tacitamente ao aderir à organização. Nesse caso, "as pessoas podem perceber que o artefato não oferece affordance para ação, restringindo sua habilidade de levar adiante seus objetivos" (LEONARDI, 2010, p. 6).

A segunda conceituação refere-se à materialidade como uma instância prática de uma ideia teórica. O autor comenta que um artefato, seja físico ou não físico, possui materialidade ao traduzir ideia em ação. Nesse sentido, a materialidade encontra-se na capacidade do uso do artefato ser traduzido em ação. Considerando esse entendimento, a materialidade deixa de estar relacionada apenas a aspectos físicos materiais podendo, dessa forma, estar presente em artefatos tecnológicos não físicos. É possível observar no modelo DAO que as regras do contrato são instanciadas no artefato smart contract, materializando o modelo de governança, para que sua actância seja exercida no controle dos membros da organização autônoma. Práticas sociais são influenciadas pela materialidade artefactual que não é exclusiva das 'coisas tangíveis'. Softwares são artefatos tecnológicos não físicos, ou seja, 'coisas intangíveis' que possuem materialidade na medida em que influenciam práticas organizacionais. Segundo o autor (p. 8), "o software claramente auxilia o instanciamento das ideias abstratas do gerenciamento". 


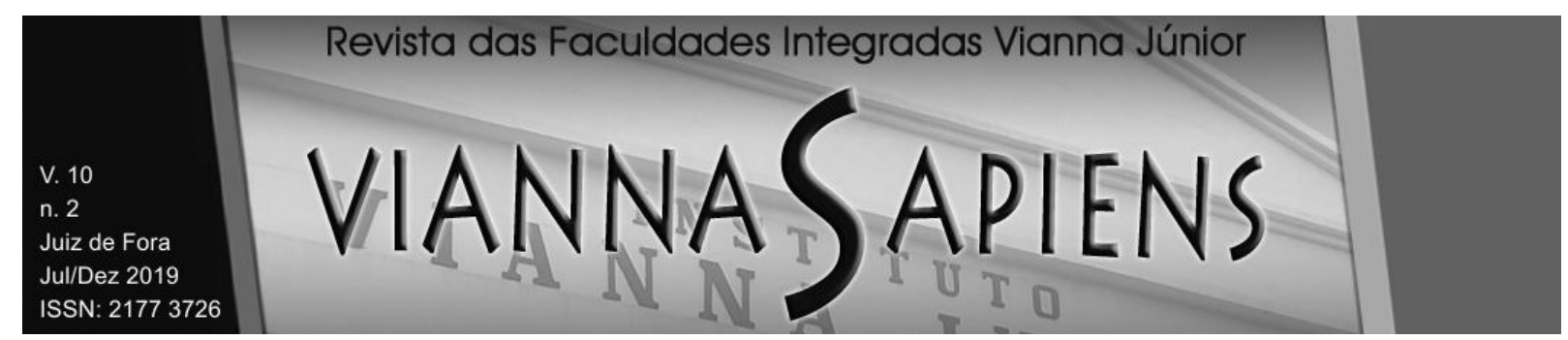

Por fim, a última conceituação apresenta materialidade como significância. Nessa ótica, apenas é material aquilo que promove alguma diferença na situação corrente. A materialidade sob a perspectiva da significância pode ser melhor compreendida a partir dos conceitos de 'artefato tecnológico' e de 'tecnologia na prática' (ORLIKOWSKI, 2000). Um artefato tecnológico é a 'coisa' utilizada pelas pessoas, enquanto a 'tecnologia na prática' é a forma como a tecnologia é utilizada. O autor se vale do exemplo de uma cadeira para exemplificar essa abordagem: uma cadeira é um artefato tecnológico independentemente do contexto do qual faz parte, contudo, pode ser usada com a função de escada em determinada circunstância como o uso da tecnologia na prática. No caso apresentado do The DAO, o modelo autônomo tinha o propósito de gerenciar um fundo de risco para investimentos em startups tecnológicas. O smart contract controlava os dois tipos de membros: investidores e empreendedores. Sob essa perspectiva, é possível considerar que o software possui diferentes funcionalidades dependendo do usuário. Para o usuário investidor, a significância do artefato relaciona-se com oportunidades de investimento, enquanto para o usuário empreendedor, a significância relaciona-se com captação financeira. Nessa análise, as funcionalidades são 'matérias', ou seja, partes da materialidade do artefato tecnológico que tem sua significância determinada pelo usuário em função do seu perfil e objetivo.

\subsection{Reflexão 2: A centralidade do artefato smart contract no modelo DAO}

O funcionamento do modelo DAO é centrado no artefato smart contract que coordena e media as ações dos membros da organização com base no modelo de governança estabelecido. Para se analisar a organização sob a ótica da sociomaterialidade, é necessário compreender alguns aspectos do smart contract e de suas interações com outras entidades do modelo. Este artefato impõe um alto grau de restrições à agência humana dos membros da DAO, objetivando garantir que os mecanismos de consenso e regras de votação definidas sejam seguidos. Percebe-se nesse modelo uma forte agência material do software que exerce um 


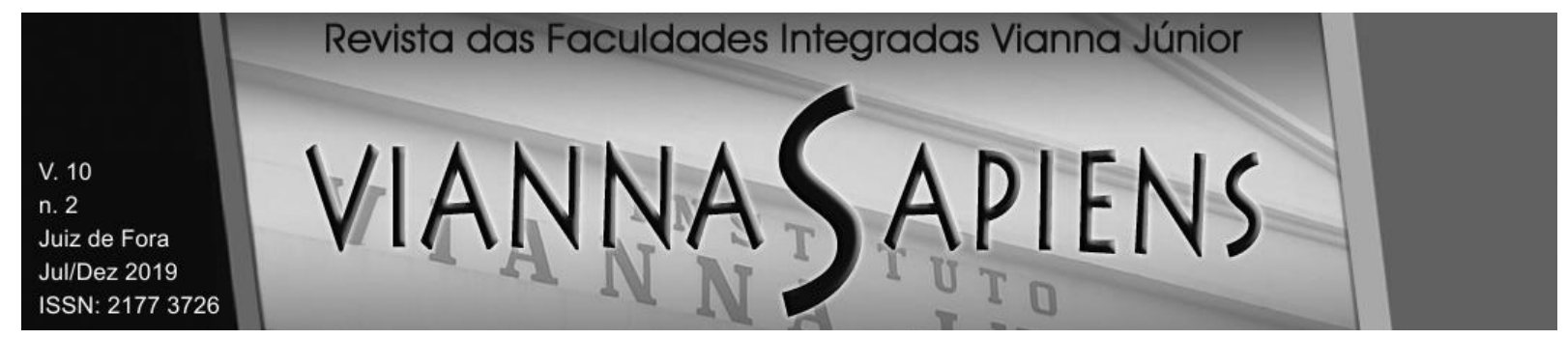

papel rígido e determinístico com alto poder de influência nas rotinas organizacionais criadas na organização.

Considerando que o smart contract é um software de funcionamento autônomo, que executará perpetuamente e cujo código não poderá ser alterado, a criação do artefato é preponderante para o funcionamento adequado da organização autônoma. A agência humana do projetista do software é determinante em um processo conhecido por inscription, no qual as regras do contrato, definidas no modelo de governança, serão codificadas e embarcadas no artefato tecnológico.

D’Adderio (2011) apresenta duas características-chave para rotinas formais como inscriptions. A primeira característica é a 'não neutralidade' do artefato, a qual é possível ser constatada no propósito do smart contract. Os projetistas do software têm como objetivo refletir no código, a partir de regras embarcadas que definirão o funcionamento futuro com os agentes humanos das rotinas. Como no contrato inteligente 'o código é lei', entende-se que o artefato tecnológico tem o poder de impor a lei aos membros da DAO. Segundo Latour (1987), artefatos tecnológicos são prescritivos na medida em que são construídos a partir da intenção de seus projetistas.

A segunda característica refere-se ao quanto o artefato é 'seletivo', isto é, em como a tecnologia é construída refletindo uma lógica racional escolhida pelos desenvolvedores que permanecerá presente enquanto 0 artefato for usado. D’Adderio (2011) destaca a relevância dessa característica no qual o aspecto performativo é resultado de agentes humanos que se inter-relacionam com artefatos tecnológicos criados por outros agentes humanos. No caso, o contrato inteligente é gerado por um processo de inscription que implementa um modelo de governança embarcado por seus desenvolvedores que codificam regras de funcionamento imutáveis. Reconhece-se, então, que a agência humana pode estar embarcada nos artefatos como uma agência material. 


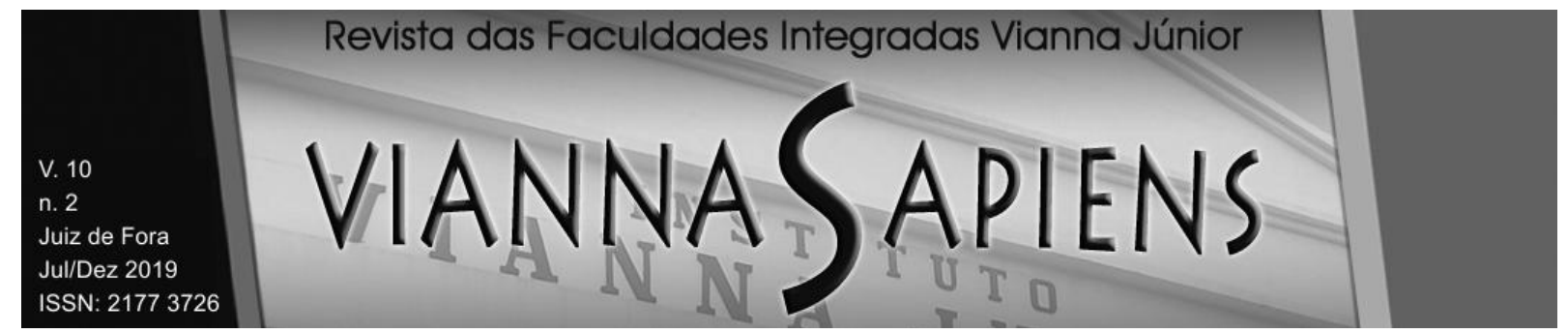

\subsection{Reflexão 3: A dualidade da estrutura e agência no modelo DAO}

Apesar das organizações autônomas e descentralizadas serem arranjos recentes e que necessitam de pesquisas de campo detalhadas para observações mais precisas, esse estudo analisa o caso The DAO, apresentado no item 2.1 do Referencial Teórico, para discutir alguns aspectos referentes ao modelo organizacional sob a ótica da sociomaterialidade. Como as práticas organizacionais são consideradas fenômenos sociais que incorporam a dualidade de estrutura e agência (GIDDENS, 1984), encontrou-se situações de interesse ao longo da análise do caso.

A DAO é uma organização estruturada para funcionar com base em uma relação social estável e, pressupostamente, sem conflitos entre seus membros. Previamente ao início da operação, é necessário aos membros fundadores da organização elaborarem um modelo de governança que oriente a construção do contrato inteligente. Como as regras, uma vez definidas, não poderão ser alteradas após o início da operação, mecanismos de consenso devem ser pensados no momento da pré-ativação, para que sejam codificadas no smart contract. Membros que voluntariamente se associarem à organização devem conhecer plenamente as regras contratuais pois entende-se que a adesão à organização acaba sendo um aceite tácito ao contrato.

Considerando que as organizações corporativas são entidades regidas por regulamentos e regras, mas conduzidas por pessoas, há duas situações que podem ocorrer: (1) pessoas violam regras e (2) pessoas nem sempre concordam com regras que foram estabelecidas. No caso de organizações regidas por modelos tradicionais de relacionamento, busca-se instâncias hierárquicas superiores ou a esfera jurídica para solucionar situações de discordâncias, fraudes e violações. Ao analisarmos a DAO, observa-se que esse tipo de encaminhamento não é possível. O modelo de organização descentralizada com base em uma tecnologia que opera autonomamente premissa que os mecanismos de relacionamento entre pessoas dispensem a necessidade de entidades externas para julgar eventuais conflitos. 


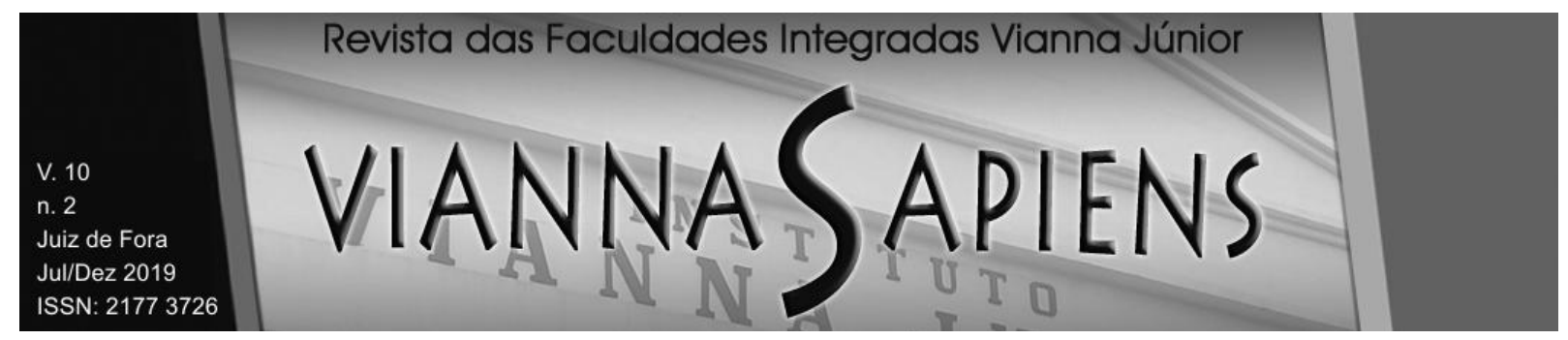

O modelo DAO é estruturado para que o smart contract seja um artefato tecnológico central com forte actância para garantir um relacionamento social controlado e estável. Nesse sentido, parece não haver recursividade no imbricamento do modelo envolvendo a agência dos membros da organização com o artefato smart contract. A agência material é constante e pouco variável por conta da imutabilidade do código. Como consequência, o imbricamento parece não provocar mudanças frequentes nas práticas organizacionais. Esta situação pode ser considerada um caso de exceção de inflexibilidade tecnológica. Leonardi (2013, p. 7) comenta que "pessoas trabalham ativamente, dentro da estrutura estabelecida por imbricações anteriores, para reconciliar seus objetivos (agência humana) com o que uma tecnologia pode ou não pode proporcionar (material)", entretanto, no caso da DAO, a agência humana torna-se bastante limitada.

Apesar dessa inflexibilidade artefactual que caracteriza o modelo, no caso The DAO, houve uma violação na estabilidade social da organização a partir da ação de um hacker que explorou uma vulnerabilidade no código do smart contract, como consequência, cerca de US\$ 56 milhões foram desviados. É possível interpretar esse evento como um incidente desestruturante na organização, a partir de uma agência humana inesperada. A agência humana de um hacker explorou uma falha no artefato tecnológico ocasionando variação na recursividade do imbricamento (material - humano) impactando a organização.

Como reação ao incidente, membros da organização decidiram realizar uma intervenção 'desrespeitando' a autonomia organizacional. Uma intervenção técnica, conhecida como hard fork, foi realizada na blockchain para dividir a cadeia de blocos e evitar a perda financeira. A decisão polêmica gerou uma intensa desestabilização na organização autônoma com a ruptura radical na estrutura suportada pelo artefato tecnológico, assim como na organização social com discussões e desentendimentos entre os membros da The DAO. A agência do invasor, a partir da sua capacidade de explorar uma vulnerabilidade do contrato, foi capaz de modificar o artefato tecnológico rígido, imutável e desenvolvido tecnologicamente para este fim. Neste caso, foi possível observar uma dinâmica de recursividade entre as partes, na qual a 


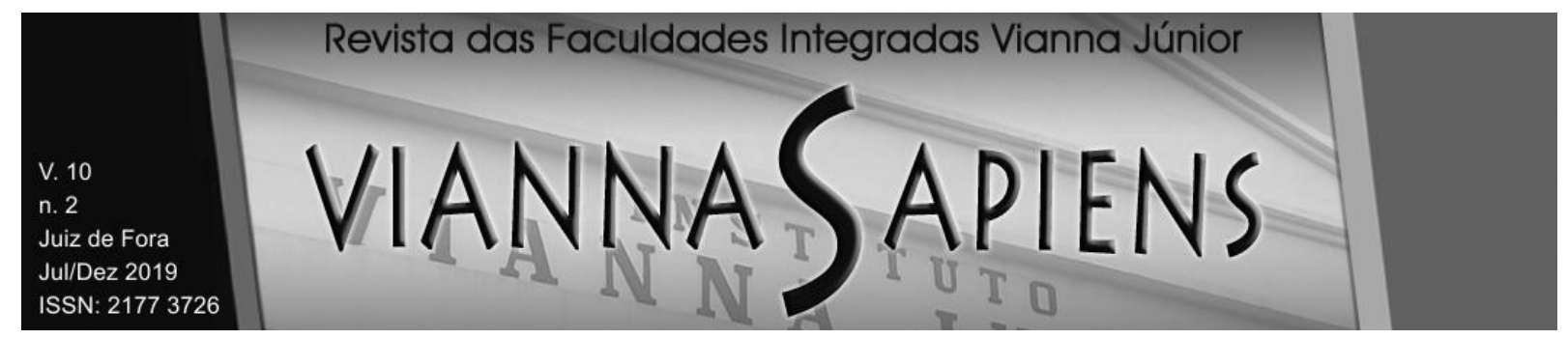

agência humana atuou como um habilitador de mudanças (EMIRBAYER e MISCHE, 1998).

\section{CONCLUSÃO}

Organizações contemporâneas cada vez mais são compreendidas como complexas, dinâmicas, distribuídas e transientes. Neste sentido, é necessário que haja novos olhares e abordagens para ajudar a teorização de fenômenos emergentes (FELDMAN e ORLIKOWSKI, 2011). Este ensaio objetivou contribuir para o estudo do impacto das novas tecnologias nas organizações a partir da seguinte pergunta de pesquisa: Quais fenômenos organizacionais podem ser identificados no modelo DAO sob a ótica da sociomaterialidade?

Com base nas reflexões apresentadas ao longo do artigo, é possível apresentar algumas conclusões finais sobre aspecto presente em um modelo organizacional autônomo e descentralizado. Identificou-se como um aspecto contundente do modelo analisado, a forte agência material do artefato smart contract, justificado pela premissa de autonomia do modelo organizacional. Como consequência, o artefato tecnológico apresenta-se com um poder para impor regras, atuando prescritivamente sobre os membros da organização e garantindo, dessa forma, controle sobre o funcionamento da organização com base no contrato definido.

Outro aspecto notório é a impossibilidade de modificação da materialidade do artefato smart contract em função da perpetuidade de execução do software em uma blockchain sem possibilidade de atualização. Por essa condição, o processo de inscription é sensível, visto que as regras do contrato definidas no software regulam a relação sociomaterial da DAO de maneira imutável.

Por fim, apesar do modelo DAO se caracterizar como um modelo estruturalista e estável com base na forte agência material, a agência humana, mesmo que sob condição limitada, pode ser fator de desestabilização da 


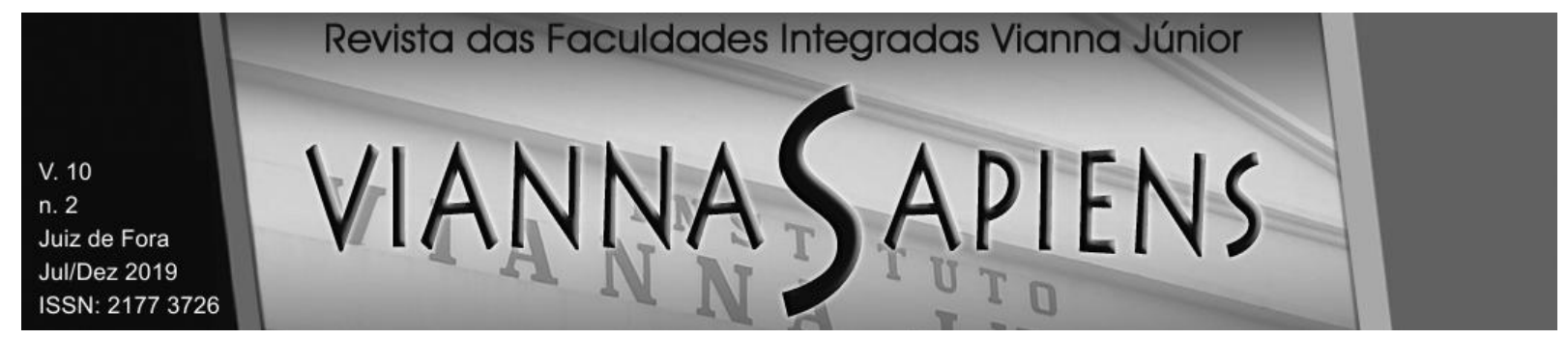

organização, como apresentado em situações de conluio entre membros da DAO e na invasão ocorrida no modelo The DAO. A partir das reflexões e conclusões realizadas sobre a relação sociomaterial do modelo DAO, pesquisas empíricas podem ser realizadas, ampliando a observação de fenômenos organizacionais nesse modelo.

Como o advento de novas tecnologias implica em transformações na constituição digital das empresas e nos seus arranjos organizacionais, novas práticas emergem enquanto outras são remodeladas. Propõe-se, assim, o aprofundamento no estudo desses novos modelos organizacionais sob a ótica da sociomaterialidade, buscando-se na investigação teórica e empírica, a identificação de fenômenos ainda inéditos. Abre-se, dessa forma, uma ampla agenda de pesquisa e algumas sugestões são apresentadas a seguir: Como novas formas de materialidade estão influenciando práticas organizacionais? Como a relação sociomaterial pode modelar práticas organizacionais que utilizam artefatos tecnológicos construídos a partir de novas tecnologias emergentes? Como modelos organizacionais são influenciados por novos artefatos tecnológicos provenientes de tecnologias emergentes?

\section{REFERÊNCIAS}

CACCIATORI, E. Resolving Conflict in Problem-Solving: Systems of Artefacts in the Development of New Routine. Journal of Management Studies, 49 (8), pp. 15591585, 2012.

CALLON, M.; MUNIESA, F. Economic Markets as Calculative Collective Devices, Organisation Studies, 26, pp. 1129-1250, 2005.

DAMERON, S.; LÊ, J. K. LEBARON, C. Materializing Strategy and Strategizing Material: Why Matter Matters. British Journal of Management, 26, S1-S12, 2015. 


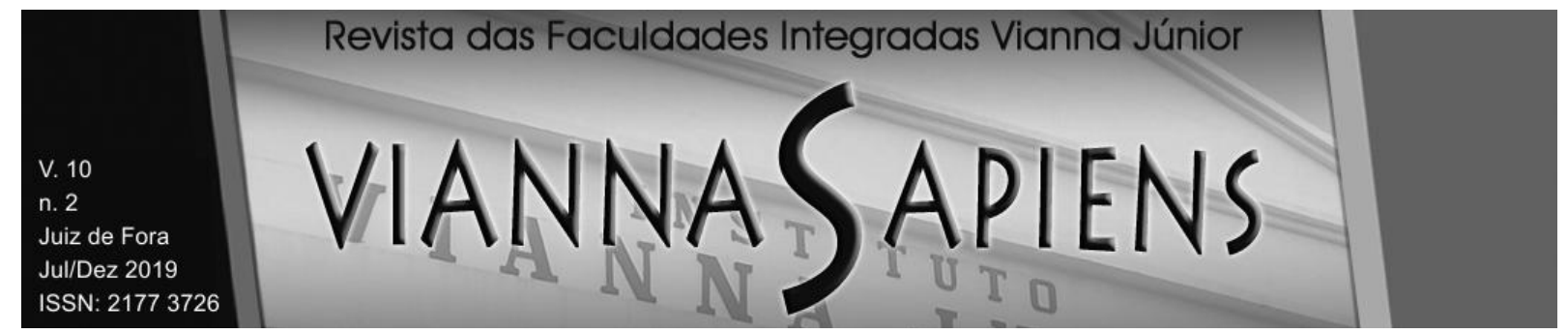

D'ADDERIO, L. Artifacts at the Centre of Routines: Performing the Material Turn in Routines Theory. Journal of Institutional Economics, 7: 2, 197-230, 2011.

The Replication Dilemma Unravelled: How Organizations Enact Multiple

Goals in Routine Transfer. Organization Science 25(5):1325-1350, 2014.

Disponível em: https://doi.org/10.1287/orsc.2014.0913. Acesso em: 1 Set. de 2019.

DUPONT, Q. Experiments in Algorithmic Governance: A history and ethnography of "The DAO," a failed Decentralized Autonomous Organization. In: Campbell-Verduyn, M. (ed.). Bitcon and Beyond - Cryptocurrencies, Blockchains and Global

Governance. New York: Routledge, 2017, cap. 8.

EMIRBAYER, M.; MISCHE, A. What Is Agency? American Journal of Sociology, 103(4): 962-1023, 1998.

FELDMAN, M. A performative perspective on stability and change in organizational routines. Industrial and Corporate Change. v. 12(4), p. 727-752, 2003.

ORLIKOWSKI, W. J. Theorizing practice and practicing theory.

Organization Science, v. 22(5), p. 1240-1253, 2011.

GHERARDI, S. Organizational Learning: The Sociology of Practice. In. EasterbySmith, M. Lyles, M. The Blackwell Handbook of Organizational Learning and Knowledge Management. Blackwell Publishing, 2011.

GIDDENS, A. A constituição da sociedade. Rio de Janeiro: Martins Fontes, 1984.

GONÇALVES, P. V. R.; CAMARGOS, R. C. Blockchain, Smart Contracts e "Judge as a Service" no Direito Brasileiro. In: II Seminário Governança das Redes e o Marco Civil da Internet: globalização, tecnologias e conectividade. Anais. Belo Horizonte: Instituto de Referência em Internet e Sociedade - IRIS, 2017. p. 207-212.

HANADA, Y; HSIAO, L.; LEVIS, P. "Smart contracts for machine-to-machine communication: Possibilities and limitations", 2018 IEEE International Conference on Internet of Things and Intelligence System (IOTAIS), pp. 130-136, Nov 2018. 


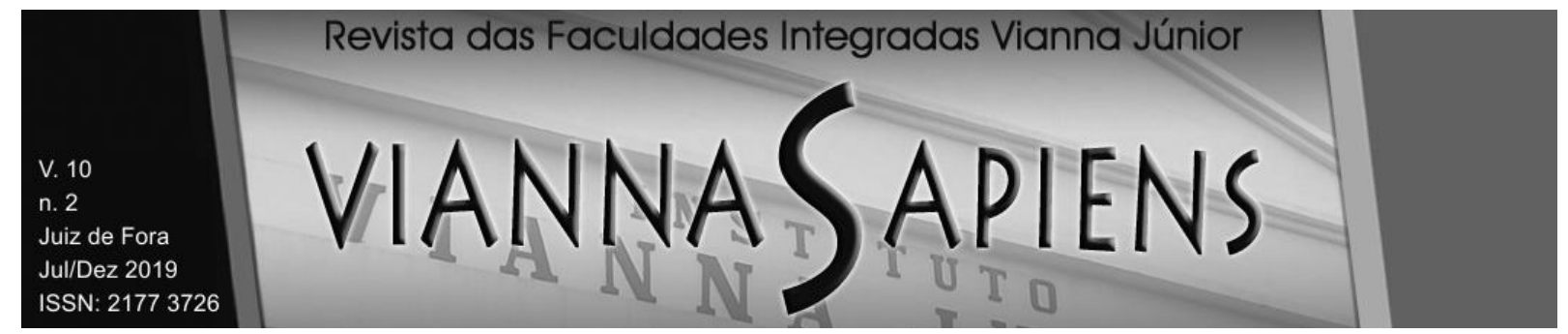

JENTZSCH, C. Decentralized autonomous organization to automate governance. Disponível em: https://download.slock.it/public/DAO/WhitePaper.pdf. Acesso em: 15 jan. de 2019.

JONES, M. R. "Information systems and the double mangle: Steering a course between the scylla of embedded structure and the charybdis of material agency". In Information systems: Current issues and future challenges, Edited by: Larsen, T., Levine, L. and DeGross, J.I. 287-302. Laxenburg: International Federation for Information Processing, 1998.

KATENTE, M. DURBE, S. Information technology governance in decentralised autonomous organisations. Disponível em: http://hdl.handle.net/10210/288785. Acesso em: 1 set. de 2019.

KUHN, T; ASHCRAFT, K.; COOREN, F. The Work of Communication: Relational Perspectives on Working and Organizing in Contemporary Capitalism, Routledge, New York, 2017.

LATOUR, B. Science in Action, Cambridge, MA: Harvard University, 1987.

LAVE, J. Cognition in Practice: Mind, Mathematics, and Culture in Everyday Life. Cambridge: Cambridge University Press, 1988.

LEONARDI, P. What is "materiality?". First Monday - Peer reviewd Journal on the Internet, vol. 15, num. 6-7, 2010. Disponível em: https://firstmonday.org/ojs/ index.php/fm/issue/view/623. Acesso em: 15 jan. de 2019.

When flexible routines meet flexible technologies: Affordance, constraint, and the imbrication of human and material agencies. MIS quarterly, v. 35, n. 1, p. 147-167, 2011.

Materiality, sociomateriality, and socio-technical systems: What do these terms mean? How are they related? Do we need them? P.M. Leonardi, B.A. Nardi, J. Kallinikos (Eds.), Materiality and organizing: Social interaction in a technological world, Oxford University Press, Oxford, pp. 25-48, 2012. 


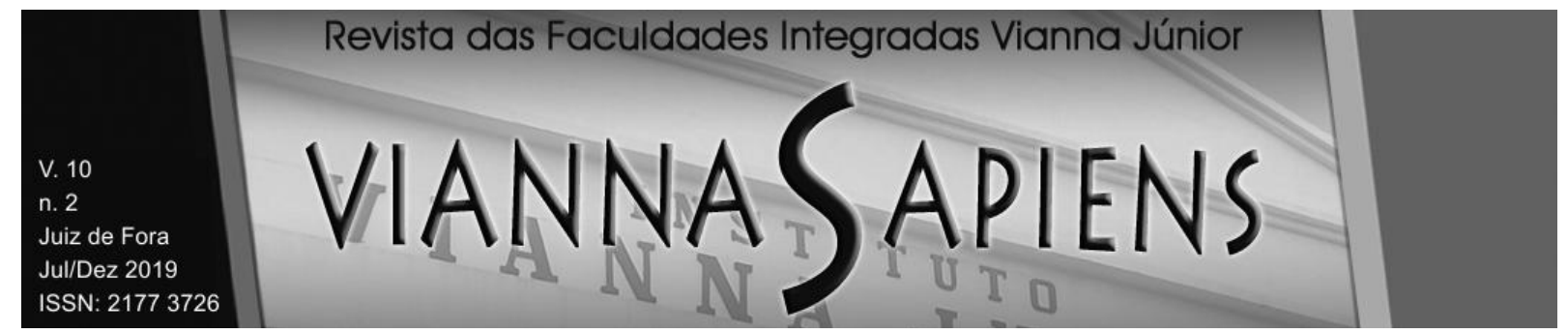

. "Theoretical Foundations for the Study of Sociomateriality," Information and Organization (23), pp. 59-76, 2013.

. BARLEY, S. What's Under Construction Here? Social Action, Materiality, and Power in Constructivist Studies of Technology and Organizing, The Academy of Management Annals, 4:1, pp 1-51, 2010.

LESSIG, L. "Code is Law." Harvard Magazine, 1999. Disponível em: <http://harvardmagazine.com/2000/01/code-is-law-html>. Acesso em: 15 jan. de 2019.

MENEGHETTI, F. O que é um Ensaio-Teórico? Revista de Administração Contemporânea, Curitiba, v. 15, n.2, pp. 320-332, 2011.

NAKAMOTO, S. Bitcoin: A Peer-to-Peer Electronic Cash System, 2008. Disponível em:< https://bitcoin.org/bitcoin.pdf.> Acesso em: 15 jan. de 2019.

ORLIKOWSKI, W. J. 'Using Technology and Constituting Structures: A Practice Lens for Studying Technology in Organizations', Organization Science, 11(4): 404-428, 2000.

Sociomaterial practices: Exploring technology at work. Organization Studies, v. 28, n. 9, p.1435-1448, 2007.

SCOTT, S. "Digital Work: A Research Agenda." A Research Agenda for Management and Organization Studies. Ed. Barbara Czarniawska. Northampton, MA: Edward Elgar Publishing, p.88-96, 2016.

SUCHMAN, L. Human-Machine Reconfigurations: Plans and Situated Actions (2 edition). Cambridge; New York: Cambridge University Press, 2000.

SZABO, N. Formalizing and Securing Relationships on Public Networks. Journal on the Internet. First Monday, Volume 2, Number 9 - 1, September,1997. 


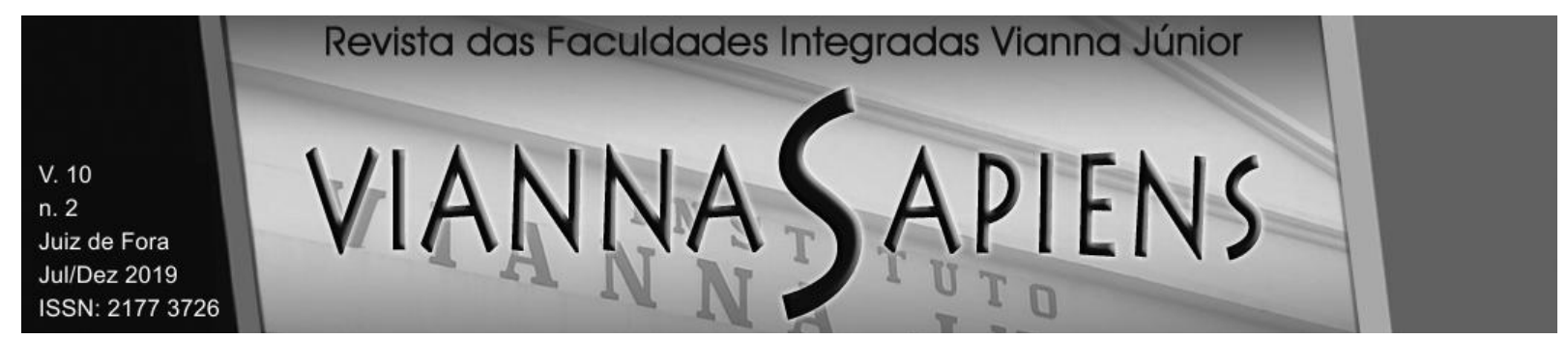

TAYLOR, J. R.; GROLEAU, C.; HEATON, L.; VAN EVERY, E. "Communication as the Modality of Structuration", in Theorizing Communication Readings Across Traditions, R. T. Craig and H. L. Mueller (eds.), Thousand Oaks, CA: Sage Publications, pp. 391-404, 2007.

VERGARA, S. Projetos e Relatórios de Pesquisa em Administração, 16 ed., São Paulo: Atlas, 2016.

YOO, Y.; BOLAND Jr., R.; LYYTINEN, K.; MAJCHRZAK, A. Organizing for Innovation in the Digitized World. Organization Science, vol. 23, No. 5, SeptemberOctober, pp. 1398-1408, 2012.

ZAMMUTO, R.; GRIFFITH, T.; MAJCHRZAK, A.; DOUGHERTY, D.; FARAJ, S. Information technology and the changing fabric of organization. Organization Science. 18(5), pp. 749-762, 2007.

Recebido em 09/09/2019

Publicado em 31/10/2019 